OPEN ACCESS

Edited by:

Claudio Fiorino,

San Raffaele Hospital (IRCCS), Italy

Reviewed by:

Jian-Guo Zhou,

University of Erlangen Nuremberg,

Germany

Dalong Pang,

Georgetown University, United States

*Correspondence:

Guillaume Dupic

guillaume.dupic@clermont.unicancer.fr

Specialty section:

This article was submitted to

Radiation Oncology,

a section of the journal

Frontiers in Oncology

Received: 15 November 2019

Accepted: 21 July 2020

Published: 11 August 2020

Citation:

Dupic G, Biau J, Molnar I, Chassin V, Dedieu V, Lapeyre M and Bellière-Calandry A (2020) Significant Correlation Between Overall Survival and Mean Lung Dose in Lung Stereotactic Body Radiation Therapy (SBRT). Front. Oncol. 10:1577. doi: 10.3389/fonc.2020.01577

\section{Significant Correlation Between Overall Survival and Mean Lung Dose in Lung Stereotactic Body Radiation Therapy (SBRT)}

\author{
Guillaume Dupic ${ }^{*}$, Julian Biau ${ }^{1}$, loana Molnar ${ }^{2,3}$, Vincent Chassin ${ }^{4}$, Véronique Dedieu${ }^{4}$, \\ Michel Lapeyre ${ }^{1}$ and Aurélie Bellière-Calandry ${ }^{1}$ \\ 1 Department of Radiation Oncology, University of Clermont Auvergne, Jean Perrin Center, Clermont-Ferrand, France, \\ 2 INSERM U1240 IMOST, University of Clermont Auvergne, Clermont-Ferrand, France, ${ }^{3}$ Department of Clinical Research \\ UMR 501, Jean Perrin Center, Clermont-Ferrand, France, ${ }^{4}$ Department of Medical Physics, University of Clermont \\ Auvergne, Jean Perrin Center, Clermont-Ferrand, France
}

Background: After stereotactic body radiation therapy (SBRT) for medically inoperable stage I non-small-cell lung cancer (NSCLC), more patients die of comorbidities, particularly severe pulmonary insufficiency, than of tumor progression. The aim of this study was to evaluate correlation between lung biologically effective dose (BED) with an $\alpha / \beta$ ratio of 3 Gy $\left(\mathrm{BED}_{3}\right)$ and overall survival $(\mathrm{OS})$ for these patients.

Methods: From 2012 to 2017, we have developed a prospectively updated institutional database for all first 100 consecutively treated patients with inoperable Stage 1 (T1T2NOM0) NSCLC. All SBRT were conducted on a Novalis Tx ${ }^{\circledR}$ LINAC with two coplanar dynamic conformal arcs (84\%) or with coplanar volumetric modulated arc therapy (VMAT) (16\%). Mean GTV and PTV were $8.6 \mathrm{cc}$ and $50.8 \mathrm{cc}$, respectively. The marginal dose prescribed to the PTV was the $80 \%$ isodose line (IDL), i.e., 54 Gy in 3 fractions for 76 patients $\left(\mathrm{BED}_{10}=126 \mathrm{~Gy}\right.$ ) and 50 Gy in 5 fractions for 24 patients $\left(\mathrm{BED}_{10}=83.3 \mathrm{~Gy}\right)$. Pulmonary heterogeneity has been taken into account by using Monte Carlo or AAA algorithms. Median follow-up was 25 months.

Results: At 1, 2, 3 and 5 years, local control (LC) was respectively 100, 98.2, 98.2, and $77.7 \%$, and OS was respectively $83,71.2,58.1$, and $33.2 \%$ (median OS was 49 months). Significant OS prognostic factors in univariate and multivariate analysis were mean lung $\mathrm{BED}_{3}(\mathrm{HR}=1.14, p=0.01)$ and $\mathrm{PTV}$ volume $(\mathrm{HR}=1.01, p=0.004)$. A mean lung $\mathrm{BED}_{3} \leq 5$ Gy was significantly associated with a doubling of median OS from 29 months to more than 60 months (not achieved, $p=0.0068$ ). For patients with a forced expiratory volume in 1 second (FEV1) $\leq 40 \%$, a mean lung $B D_{3} \leq 4$ Gy was significantly associated with a doubling of median OS from 23 to 46 months $(p=0.019)$.

Conclusion: Mean lung $\mathrm{BED}_{3}$ is strongly and significantly associated with OS in SBRT for inoperable Stage I NSCLC. For all treated patients, a mean lung $\mathrm{BED}_{3} \leq 5$ Gy lead to a doubling of median OS. This threshold value should be reduced to 4 Gy for patients with FEV $1 \leq 40 \%$.

Keywords: lung, stereotactic radiotherapy, prognostic factor, mean lung dose, toxicity 


\section{HIGHLIGHTS}

- Grade 5 radiation pneumonitis after lung SBRT is probably under-evaluated because of poor baseline pulmonary function of treated patients.

- Mean lung $\mathrm{BED}_{3}$ is a strong and significant prognostic factor of overall survival after lung SBRT.

- Mean lung $\mathrm{BED}_{3} \leq 5$ Gy (i.e., $3.6 \mathrm{~Gy}$ in 3 fractions or $4.3 \mathrm{~Gy}$ in 5 fractions) is significantly associated with higher overall survival after lung SBRT with a doubling in median overall survival.

- For patients with poor baseline pulmonary function (FEV1 or DLCO $\leq 40 \%$ ), this threshold should be reduced to 4 Gy (i.e., 3 Gy in 3 fractions or 3.5 Gy in 5 fractions).

\section{INTRODUCTION}

Stereotactic body radiation therapy (SBRT) is the standard treatment for medically inoperable stage I non-small-cell lung cancer (NSCLC) (1). Generally, overall survival (OS) for these patients in prospective studies is around 81-100, 65-70, 39-68, and $30-65 \%$, respectively at $1,2,3$ and 5 years. Local control (LC) is high, around $86-100$ and $79-85 \%$, respectively at 3 and 5 years (1-3). It is widely agreed that more NSCLC patients treated with SBRT die of comorbidities than of tumor progression. Significant prognostic factors are age (4), gender (5), performance status $(4,6)$, histologic type (4), tumor volume (5-7), pretreatment maximum standardized uptake value $\left(\operatorname{SUV}_{\max }\right)(6,8,9)$, plateletto-lymphocyte ratio $(8,10)$, pretreatment immune parameters (neutrophil-to-lymphocyte ratio, neutrophil and lymphocyte counts) (10) and prescribed dose (11). The role of lung dosimetric parameters as prognostic factors remains unknown. After lung SBRT, many patients died from severe pulmonary insufficiency attributed to their previous medical history [OS at 5 years is $30-65 \%$ after SBRT vs. $60-80 \%$ after surgery (12)], which makes severe radiation-induced pneumonitis (RP) difficult to interpret $(2,13)$.

$\mathrm{RP}$ is the most frequent complication after lung SBRT (14). Clinically symptomatic RP seems to develop mostly in 10-20\% of patients (range: $0-49 \%$ among published studies) with most patients having asymptomatic Grade 1 pneumonitis (2, 15-17).

\footnotetext{
Abbreviations: 18F-FDG PET, 18-F FluoroDeoxyGlucose Positron Emission Tomography; BED, biologically effective dose; CBCT, cone beam CT; CI, conformality index, ratio of $80 \%$ prescription isodose volume to the PTV; CT, computed tomography; CTV, clinical target volume; D2cm, maximum dose $2 \mathrm{~cm}$ from the PTV in any direction; DCA, dynamic conformal arcs; DLCO, diffusing lung capacity for carbon monoxide; FEV1, forced expiratory volume in 1 second; GTV, gross tumor volume; Gy, Gray; ITV, internal target volume; LC, local control; LINAC, LINear ACcelator; MLD, mean lung dose; MRI, magnetic resonance imaging; NCI-CTCAE, National Cancer Institute's Common Toxicity Criteria for Adverse Events; NSCLC, non-small-cell lung cancer; NYHA, New York Heart Association; OS, overall survival; PFS, progression-free survival; PS, performance status; PTV, planning target volume; R50, ratio of 50\% prescription isodose volume to the PTV; RECIST, Response Evaluation Criteria in Solid Tumors; ROC, receiver operating characteristics; RP, radiation-induced pneumonitis; RTOG, Radiation Therapy Oncology Group; SBRT, stereotactic body radiation therapy; SUVmax, maximum standardized uptake value; TPS, treatment planning systems; VMAT, volumetric modulated arc therapy.
}

Pre-treatment pulmonary function tests have not been shown to be predictive for RP. Therefore, patients with NSCLC with a poor baseline pulmonary function are not excluded from treatment with SBRT (18). Mean lung dose (MLD) seems to be a strong and reproducible dosimetric parameter of RP, with a significant cut-off at 4-4.7 Gy in three fractions, and is often correlated to the volume of PTV $(15,17,19-21)$. Many factors may have confounded the reported MLD because of inadequate heterogeneity correction algorithms, various dose prescriptions and fractionations and probably a lack of lung volume definitions (whole or ipsilateral lung volume minus GTV or PTV) $(17,22,23)$. In this way, the biologically effective dose (BED) determined with adequate heterogeneity correction algorithms may be used for estimating toxicity probabilities. For high fraction doses, the linear-quadratic model with an $\alpha / \beta$ ratio of $3 \mathrm{~Gy}$ is the best method for converting the physical lung dose to predict RP (24).

Our study aimed to evaluate the correlation between lung $\mathrm{BED}_{3}$ and $\mathrm{OS}$ in a prospectively updated institutional cohort of 100 consecutively treated patients with stage I NSCLC. The secondary objective was to study the impact of lung dosimetric parameters in a population with a poor baseline pulmonary function.

\section{PATIENTS AND METHODS}

\section{Patients' Selection and Characteristics}

From October 2012 to August 2017, we have developed a prospectively updated institutional database for all patients consecutively treated with SBRT for inoperable Stage 1 (T1T2N0M0) NSCLC in our institution. This database has been approved by our local ethics committee and a regional ethics committee (CECIC Rhône-Alpes-Auvergne, Grenoble, IRB 5921), and developed according to the French law regulating clinical research (Loi Huriet). Thus, our study is an observational cohort study from all first 100 patients recorded in this prospectively updated institutional database. All treated patients fulfilled inclusion criteria of those first described by Timmerman et al. in the analysis of RTOG 0236 (25): performance status (PS) $\leq 2$, age $\geq 18$ years, stages T1T2N0M0, peripherally located NSCLC at least $2 \mathrm{~cm}$ from the proximal bronchial tree, and medical inoperability (baseline forced expiratory volume in one second (FEV1) $\leq 40 \%$, predictive postoperative FEV1 $\leq 30 \%$, diffusing capacity for carbon monoxide (DLCO) $\leq 40 \%$, severe cerebral, pulmonary or cardiovascular disease or patient refusal).

All patients were required to have a complete imaging screening performed less than 1 month prior to lung SBRT: a high-resolution contrast-enhanced lung computed tomography (CT), a 18F-fluorodeoxyglucose positron emission tomography (18F-FDG PET) and a cerebral magnetic resonance imaging (MRI) to exclude regional or distant metastases. A flexible bronchoscopy was needed to exclude an endobronchial location or infectious disease such as lung tuberculosis. A cytologically or histologically proven NSCLC was strongly 
recommended but not mandatory in case of contraindications. If this proof was not obtained, a tumor growth observed with an interval at least 3 months between two CT or a maximum standardized uptake value $\left(\mathrm{SUV}_{\max }\right)$ in $18 \mathrm{~F}$ FDG PET above 2.5-3 was necessary to include patients. Exclusion criteria were small-cell lung cancer, mediastinal location and no meeting of normal tissue dose constraints. Pre-treatment pulmonary function tests were performed for all patients.

All pre-treatment characteristics of the 100 included patients are reported in Table 1. Most patients were elderly [median age $=70$ years (range: 47-90)] and male (79\%) with a good general status $(93 \%$ PS $\leq 1)$ and no history of lung surgery (78\%) or radiotherapy (93\%), but with poor baseline pulmonary function [57\% NYHA (New York Heart Association) class $\geq 2$ dyspnea, median FEV1 was $62 \%$ (20-100\%) and median DLCO was 48\% (8-100\%)]. Fiftysix percent of patients had no histologically or cytologically proven NSCLC. Mean GTV was $8.6 \mathrm{cc}(0.2-61.5 \mathrm{cc})$, i.e., about $2 \mathrm{~cm}$ in diameter.

\section{SBRT Specifications}

The gross tumor volume (GTV) was contoured on 2.5-mmthick lung CT windows. Intrafraction tumor motion due to breathing was limited by an abdominal compression and taken into account by creating an internal target volume (ITV) obtained with a four-dimensional (4D) CT scan at the time of CT simulation. An additional margin of $8 \mathrm{~mm}$ for adenocarcinoma and $6 \mathrm{~mm}$ for other histologic types was added for microscopic tumor extension to create the clinical target volume (CTV) $(26,27)$. Finally, the planning target volume (PTV) was obtained with a uniform $3 \mathrm{~mm}$ CTV expansion, according to our defined geometric stereotactic conditions.

All SBRT treatment characteristics are reported in Table $\mathbf{1}$. The isocenter prescription dose was 67.5 Gy in 3 fractions and reduced to $62.5 \mathrm{~Gy}$ in 5 fractions for central lung tumors to meet normal tissue dose contraints. The marginal isodose line prescribed to the edge of PTV was the $80 \%$ isodose: respectively, $54 \mathrm{~Gy}$ in 3 fractions and 50 Gy in 5 fractions $\left(\mathrm{BED}_{10}=126 \mathrm{~Gy}\right.$ and $\left.83.3 \mathrm{~Gy}\right)$. Each fraction was separated by at least $40 \mathrm{~h}(25)$.

All treatments used 6-MV photons. Dose distributions were performed with two coplanar dynamic conformal arcs (DCA) in $84 \%$ of cases and with volumetric modulated arc therapy (VMAT) in 16\%. Treatment planning systems (TPS) were Iplan $^{\circledR}$ v4.1 (Brainlab, Feldkirchen, Germany) for DCA plans and Eclipse ${ }^{\circledR}$ v13.5 (Varian Medical Systems, Palo Alto, CA, United States) for VMAT plans. Pulmonary heterogeneity has been taken into account by using the Monte Carlo algorithm for DCA plans and the AAA algorithm for VMAT plans. Target coverage was adequate when at least 95\% of the PTV was covered by $80 \%$ of the prescribed isodose. Treatment quality was verified by calculating the conformality index (CI) (a ratio of $80 \%$ prescription isodose volume to the PTV), a ratio of $50 \%$ prescription isodose volume to the PTV (R50) and the maximum dose $2 \mathrm{~cm}$ from the PTV
TABLE 1 | Patients and SBRT characteristics.

\begin{tabular}{|c|c|}
\hline Characteristics & Number \\
\hline \multicolumn{2}{|l|}{ Patients' characteristics } \\
\hline Total & $100(100 \%)$ \\
\hline \multicolumn{2}{|l|}{ Gender } \\
\hline Female & $21(21 \%)$ \\
\hline Male & 79 (79\%) \\
\hline \multicolumn{2}{|l|}{ Age (years) } \\
\hline Mean & $71(47.1-90.4)$ \\
\hline \multicolumn{2}{|l|}{ Performance status } \\
\hline 0 & $54(54 \%)$ \\
\hline 1 & 39 (39\%) \\
\hline 2 & $7(7 \%)$ \\
\hline$\geq 3$ & $0(0 \%)$ \\
\hline \multicolumn{2}{|l|}{ Medical history } \\
\hline \multicolumn{2}{|l|}{ Surgery } \\
\hline Pneumonectomy & $4(4 \%)$ \\
\hline Lobectomy & $18(18 \%)$ \\
\hline None & $78(78 \%)$ \\
\hline \multicolumn{2}{|l|}{ Lung radiotherapy } \\
\hline Yes & $7(7 \%)$ \\
\hline No & 93 (93\%) \\
\hline \multicolumn{2}{|l|}{ Pre-treatment dyspnea (NYHA) } \\
\hline 0 & $18(18 \%)$ \\
\hline 1 & $25(25 \%)$ \\
\hline 2 & $18(18 \%)$ \\
\hline 3 & $30(30 \%)$ \\
\hline 4 & $9(9 \%)$ \\
\hline \multicolumn{2}{|l|}{ Pre-treatment pulmonary function } \\
\hline \multicolumn{2}{|l|}{ FEV1(\%) } \\
\hline Mean & $64.1(20-100)$ \\
\hline \multicolumn{2}{|l|}{ DLCO (\%) } \\
\hline Mean & $49.2(8.0-100)$ \\
\hline \multicolumn{2}{|c|}{ Characteristics of pulmonary nodules } \\
\hline \multicolumn{2}{|l|}{ Histological/cytological proof } \\
\hline None & $56(56 \%)$ \\
\hline Adenocarcinoma & $32(32 \%)$ \\
\hline Squamous cell carcinoma & $9(9 \%)$ \\
\hline Undifferentiated carcinoma & $1(1 \%)$ \\
\hline Neuroendocrine carcinoma & $2(2 \%)$ \\
\hline \multicolumn{2}{|l|}{ RTOG localization } \\
\hline Central & $7(7 \%)$ \\
\hline Peripheral & 93 (93\%) \\
\hline \multicolumn{2}{|l|}{ Pulmonary localization } \\
\hline Right upper lobe & $36(36 \%)$ \\
\hline Right middle lobe & $5(5 \%)$ \\
\hline Right lower lobe & $14(14 \%)$ \\
\hline Left upper lobe & $31(31 \%)$ \\
\hline Left lower lobe & $14(14 \%)$ \\
\hline \multicolumn{2}{|l|}{ Pre-treatment SUVmax } \\
\hline Mean & $7.5(1.2-19.5)$ \\
\hline \multicolumn{2}{|l|}{ Tumor volume } \\
\hline \multicolumn{2}{|l|}{ Longest diameter (mm) } \\
\hline Mean & $23.4(7.8-53.9)$ \\
\hline
\end{tabular}


TABLE 1 | Continued

\begin{tabular}{|c|c|}
\hline Characteristics & Number \\
\hline \multicolumn{2}{|l|}{ GTV (cc) } \\
\hline Mean & $8.6(0.2-61.5)$ \\
\hline \multicolumn{2}{|l|}{ PTV (cc) } \\
\hline Mean & $50.8(3.8-223.1)$ \\
\hline \multicolumn{2}{|l|}{ SBRT characteristics } \\
\hline \multicolumn{2}{|l|}{ Technique } \\
\hline DCA & $84(84 \%)$ \\
\hline VMAT & $16(16 \%)$ \\
\hline \multicolumn{2}{|l|}{ Fractionation } \\
\hline 3 & $76(76 \%)$ \\
\hline 5 & $24(24 \%)$ \\
\hline \multicolumn{2}{|l|}{ Overall treatment time (days) } \\
\hline Mean & $8(4-35)$ \\
\hline \multicolumn{2}{|l|}{ Isocenter prescribed BED 10 (Gy) } \\
\hline Mean & $196(100-219)$ \\
\hline \multicolumn{2}{|l|}{ Received PTV BED 10 (Gy) } \\
\hline$D_{\max }$ & $198(87-252)$ \\
\hline$D_{2} \%$ & $194(87-246)$ \\
\hline $\mathrm{D}_{98} \%$ & $137(111-165)$ \\
\hline $\mathrm{D}_{\min }$ & $110(27-166)$ \\
\hline $80 \%$ prescription isodose volume (\%) & $79(39.8-100)$ \\
\hline \multicolumn{2}{|l|}{ Treatment quality } \\
\hline Conformality index (Cl) & $1.19(1.0-1.64)$ \\
\hline $\mathrm{R} 50$ & $1.8(0.46-5.72)$ \\
\hline D2cm (Gy) & $36.6(22.7-57.5)$ \\
\hline \multicolumn{2}{|l|}{ Follow-up (months) } \\
\hline Mean & $27(0.6-64)$ \\
\hline Median & $25(0.6-64)$ \\
\hline
\end{tabular}

NHYA: New York Heart Association, SUVmax: maximum Standardized Uptake Value, FEV1: Forced Expiratory Volume in 1 second, DLCO: Diffusing Lung capacity for Carbon Monoxide, DCA: Dynamic Conformal Arcs, VMAT: volumetric modulated arc therapy, $B E D 10=$ biologically effective dose with an $\alpha / \beta$ ratio of $10 \mathrm{~Gy}$, Conformality Index (CI): ratio of $80 \%$ prescription isodose volume to the $P T V, R 50$ : ratio of $50 \%$ prescription isodose volume to the $P T V, D 2 \mathrm{~cm}$ : maximum dose $2 \mathrm{~cm}$ from the PTV in any direction.

in any direction (D2cm), as seen in Table 1 (28). Lung SBRT was performed using a Novalis $\mathrm{Tx}^{\circledR}$ (Varian Medical Systems, Palo Alto, CA, United States) linear accelator (LINAC) with an integrated Exactrac X-ray 6D system $^{\circledR}$ (Brainlab AG, Feldkirchen, Germany). This system enabled a pretreatment positioning which was then adjusted daily with a Cone Beam CT (CBCT).

\section{Follow-Up}

Follow-up included prospective clinical examination and CT scans every 3 months during the first two years post-SBRT and every 6 months afterward. Follow-up PET scans were required only in cases of progressive soft tissue abnormalities observed on CT. Efficacy was assessed with the Response Evaluation Criteria in Solid Tumors (RECIST) (29). A complete response was defined as the disappearance of the target lesion, a partial response as a decrease of at least $30 \%$ of the tumor's longest diameter and a progressive disease as an increase of at least $20 \%$ of the longest diameter. LC was defined as the absence of local failure. Local failure was characterized as the combination of a RECIST progressive disease and evidence of tumor viability as shown by biopsy or $S_{\text {max }}$ in 18F-FDG PET above the pre-treatment $S_{\text {max }}$ or above a value of 5 (30). Progression-free survival (PFS) was defined as the period of time from the end of SBRT to the date of local-regional failure, disseminated (visceral or lymphnode) recurrence or the patient's death. OS was defined as the time between the end of SBRT and the patient's death. Toxicity was evaluated with the National Cancer Institute's Common Toxicity Criteria for Adverse Events version 4.0 (NCICTCAE).

Mean and median follow-up were respectively 27 and 25 months (range: 0.6-64). Only one patient was lost to follow-up after 10 months (Table $\mathbf{1}$ ).

\section{Statistical Analysis}

No patient included in the prospectively updated institutional database of all first 100 patients consecutively treated with SBRT in our institution was excluded from the study or from the statistical analysis (Figure 1). LC, PFS, and OS were calculated using the Kaplan-Meier method. The Cox proportional hazards model was performed to identify predictive factors of LC and prognostic factors of PFS and OS. A twosided $p$-value $<0.05$ was considered significant. The following factors were included in the univariate analysis for LC: histological type, pre-treatment $\mathrm{SUV}_{\max }$, conformality index, R50, GTV, PTV, an 80\% prescription isodose volume (\%), and maximum and minimum PTV $\mathrm{BED}_{10}\left(\mathrm{D}_{\max }, \mathrm{D}_{98} \%\right.$, $\left.\mathrm{D}_{2} \%, \mathrm{D}_{\min }\right)$. Concerning PFS and OS, the following factors were included in the univariate analysis in addition to the previously studied LC predictive factors: gender, age, performance status, history of lung surgery, pre-treatment FEV1, pre-treatment DLCO, baseline pulmonary function, and mean lung $\mathrm{BED}_{3}$ (whole lungs, ipsilateral lung, whole lungs minus PTV, ipsilateral lung minus PTV), The BenjaminiHochberg method was used to adjust $p$-values to limit false positives, considering the large number of tests. The Spearman correlation enabled the identification of strongly correlated factors between them that were not included in the multivariate analysis (Spearman's rank correlation coefficient of 0.75). Factors associated with a $p$-value $<0.25$ in the univariate analysis were included in the multivariate analysis if they were also selected by the LASSO method. The Wald test and the Likelihood ratio test were performed to calculate and verify the $p$-value for each coefficient in multivariate analyses.

Linear correlation between OS and significant prognostic factors was then verified with a Pearson or Spearman correlation coefficient, depending on the cases, especially for patients with a poor pre-treatment pulmonary function (i.e., FEV1 or DLCO $\leq 40 \%)$. For each significant linear correlation observed, a ROC (Receiver Operating Characteristics) curve was performed to identify the best threshold. Finally, comparisons of OS curves with obtained thresholds were conducted using the logrank test. 
Assessed for eligibility $(\mathrm{n}=100)$

Excluded $(\mathrm{n}=0)$

- Not meeting inclusion criteria $(\mathrm{n}=0)$

- Declined to participate $(\mathrm{n}=0)$

- Other reasons $(\mathrm{n}=0)$

Allocated to lung SBRT $(\mathrm{n}=100)$

- Received allocated SBRT $(\mathrm{n}=100)$

- Did not receive allocated $\operatorname{SBRT}(\mathrm{n}=0)$

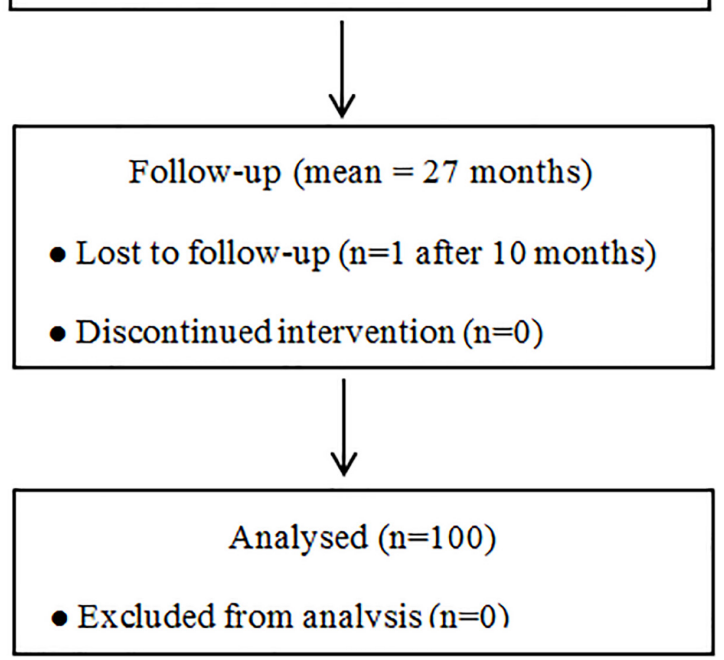

FIGURE 1 | Flowchart of the patient enrollment process of study cohort.

\section{RESULTS}

\section{Local Control and Progression-Free Survival}

Local control at 1, 2, 3, and 5 years was respectively 100, 98.2, 98.2, and 77.7\% (Figure 2). Three local failures were observed. No statistically significant predictive factor of LC was found (Table 2). PFS at 1, 2, 3, and 5 years was respectively 80, 55.1, 43.7, and 19.7\% (Figure 2). Median PFS was 28 months (CI95\%: 22-51 months). PFS after lung SBRT was significantly correlated to tumor volume $(\mathrm{GTV})$ in univariate analysis $(\mathrm{HR}=1.065$, $95 \% \mathrm{CI}=1.040-1.091, p<0.001)$ and in multivariate analysis $(\mathrm{HR}=1.060,95 \% \mathrm{CI}=1.033-1.087, p<0.001)$, as shown in Table 2. There was a strong trend for significance when we studied mean ipsilateral lung $\mathrm{BED}_{3}$ ( $p$-value of $0.063 ; \mathrm{HR}=2.035$, $95 \% \mathrm{CI}=1.000-1.072$ ).

\section{Overall Survival}

Overall survival at $1,2,3$, and 5 years was respectively 83 , 71.2, 58.1, and 33.2\% (Figure 2). Median OS was 49 months. In univariate analysis, significant prognostic factors of OS were GTV $(\mathrm{HR}=1.074,95 \% \mathrm{CI}=1.047-1.102, p<0.001), \mathrm{PTV}(\mathrm{HR}=1.016$, $95 \% \mathrm{CI}=1.010-1.022, p<0.001)$, mean lung $\mathrm{BED}_{3}(\mathrm{HR}=1.125$, $95 \% \mathrm{CI}=1.033-1.225, p=0.04)$, mean ipsilateral lung $\mathrm{BED}_{3}$ $(\mathrm{HR}=1.060,95 \% \mathrm{CI}=1.020-1.103, p=0.04)$ and mean ipsilateral lung minus $\mathrm{PTV} \mathrm{BED}_{3}(\mathrm{HR}=1.087,95 \% \mathrm{CI}=1.023-1.156$, $p=0.04)$. Prognostic factors of OS that remained significant in multivariate analysis were mean lung $\mathrm{BED}_{3}(\mathrm{HR}=1.14$, 
A

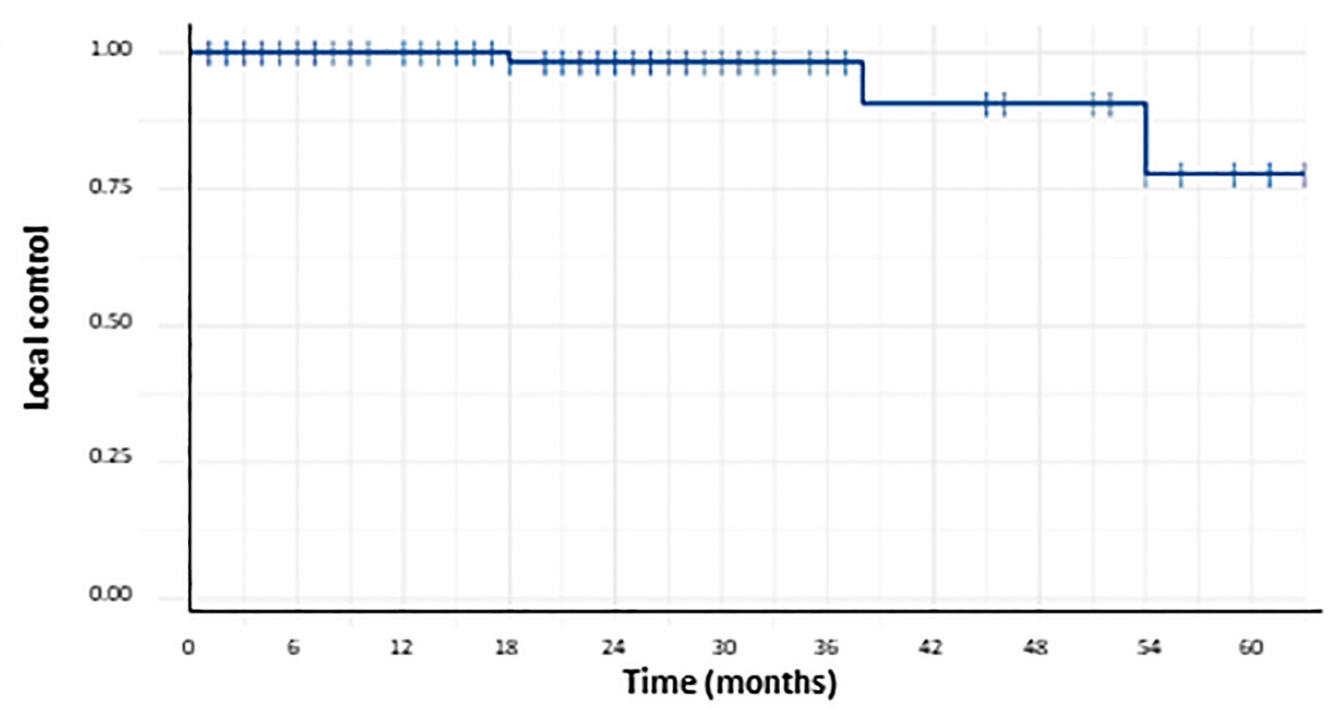

B

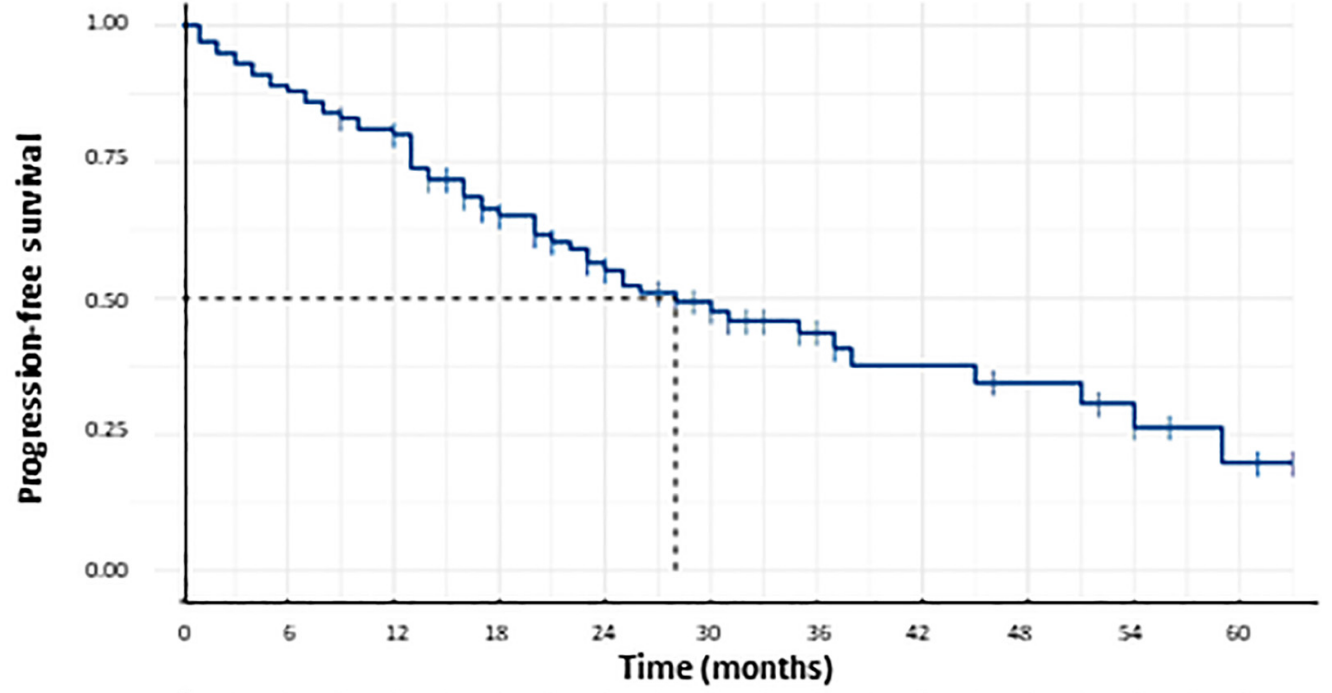

C

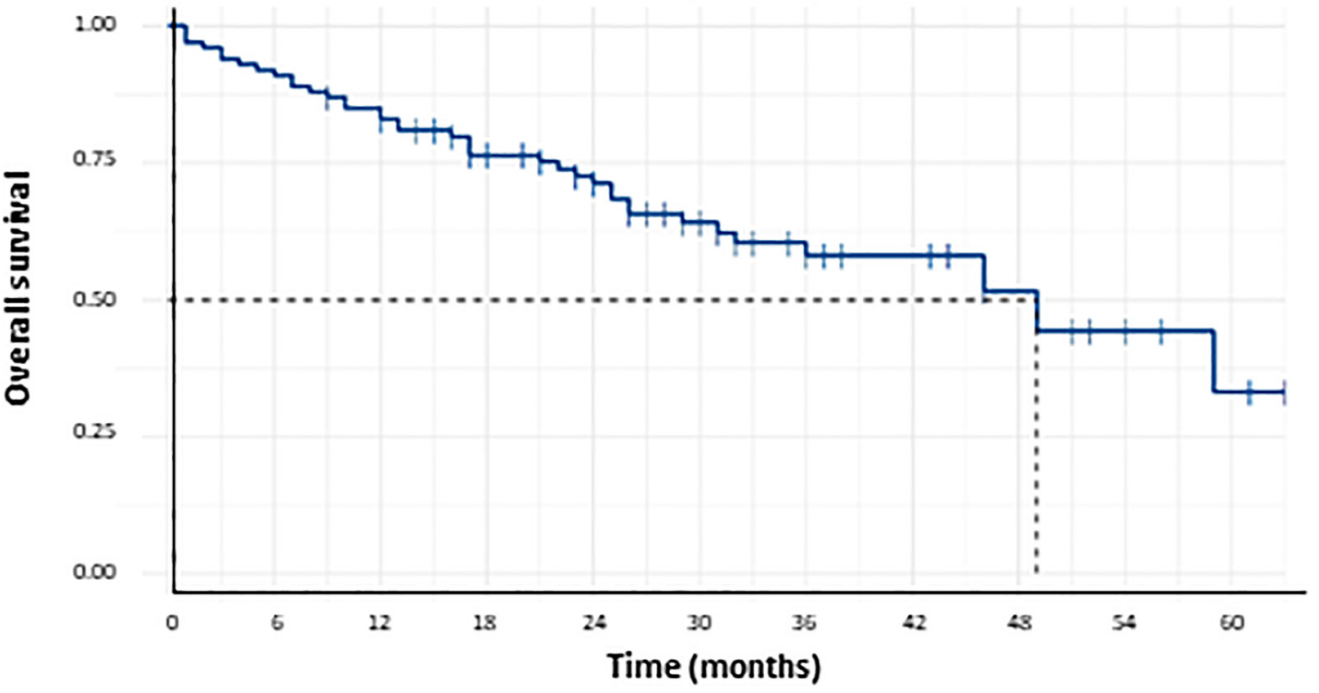

FIGURE 2 | Probability of local control (A), probability of progression-free survival (B) and probability of overall survival (C) for the 100 patients receiving lung SBRT for Stage I NSCLC. 
TABLE 2 | Results of univariate and multivariate analyses for local control, progression-free survival, overall survival and radiation pneumonitis incidence.

\begin{tabular}{|c|c|c|c|c|c|c|c|c|}
\hline & \multicolumn{4}{|c|}{ Univariate analysis (LR p BH) } & \multicolumn{4}{|c|}{ Multivariate analysis (W p) } \\
\hline & LC & PFS & os & $\mathbf{R P}$ & LC & PFS & os & $\mathbf{R P}$ \\
\hline Pre-treatment SUVmax & 0.92 & 0.96 & 0.79 & - & - & - & - & - \\
\hline Conformality index & 0.92 & 0.21 & 0.32 & - & - & - & - & - \\
\hline R50 & 0.92 & 0.95 & 0.85 & - & - & - & - & - \\
\hline $80 \%$ prescription isodose volume & 0.92 & 0.21 & 0.14 & - & - & - & - & - \\
\hline \multicolumn{9}{|l|}{ PTV BED $_{10}$} \\
\hline$D_{\max }$ & 0.92 & 0.51 & 0.66 & - & - & - & - & - \\
\hline$D_{2 \%}$ & 0.92 & 0.56 & 0.66 & - & - & - & - & - \\
\hline$D_{98 \%}$ & 0.92 & 0.80 & 0.79 & - & - & - & - & - \\
\hline Performans status & - & 0.56 & 0.38 & - & - & - & - & - \\
\hline \multicolumn{9}{|l|}{ Past medical history of } \\
\hline Lung surgery & - & 0.95 & 0.79 & - & - & - & - & - \\
\hline Lung radiotherapy & - & 0.80 & 0.66 & - & - & - & - & - \\
\hline \multicolumn{9}{|l|}{ Pre-treatment } \\
\hline FEV1 & - & 0.80 & 0.58 & $<0.001$ & - & - & - & 0.003 \\
\hline DLCO & - & 0.49 & 0.18 & $<0.001$ & - & - & 0.07 & 0.015 \\
\hline Level of dyspnea (NYHA) & - & 0.80 & 0.65 & - & - & - & - & - \\
\hline \multicolumn{9}{|l|}{ Mean lung $\mathrm{BED}_{3}$} \\
\hline Whole lungs & - & 0.32 & 0.04 & 0.09 & - & - & 0.01 & - \\
\hline Ipsilateral lung & - & 0.23 & 0.04 & 0.04 & - & - & - & - \\
\hline
\end{tabular}

LR p BH: p-value with Likelihood ratio adjusted by Benjamini-Hochberg method, W p: p-value with Wald test, SUVmax: maximum standardized uptake value, R50: ratio of $50 \%$ prescription isodose volume to the PTV, BEDx = biologically effective dose with an $\alpha / \beta$ ratio of $\times$ Gy, FEV1: forced expiratory volume in 1 second, DLCO: diffusing lung capacity for carbon monoxide, NHYA: New York Heart Association. Bold values are those that are statistically significant.

CI95\% $=1.03-1.25, p=0.01)$ and PTV $(\mathrm{HR}=1.01, \mathrm{CI} 95 \%=1.0-$ 1.02, $p=0.004$ ), as shown in Table 2 . Subgroup analysis has been done to study the prognostic role of mean lung $\mathrm{BED}_{3}$ in OS. Concerning subgroup analysis of $\mathrm{FEV}_{1}$, mean lung $\mathrm{BED}_{3}$ remained significantly correlated to OS in multivariate analysis whether for patients with $\mathrm{FEV}_{1} \leq 40 \%(\mathrm{HR}=1.55$, $95 \% \mathrm{CI}=1.12-2.14, p=0.008)$ or with $\mathrm{FEV}_{1}>40 \%(\mathrm{HR}=1.14$, $95 \% \mathrm{CI}=1.02-1.28, p=0.021)$. Concerning subgroup analysis of GTV, mean lung $\mathrm{BED}_{3}$ remained significantly correlated to OS in multivariate analysis for patients with GTV $<$ mean GTV, i.e., $8.6 \mathrm{cc}(\mathrm{HR}=1.34,95 \% \mathrm{CI}=1.06-1.69, p=0.015)$ but not for patients with GTV $\geq$ mean GTV $(\mathrm{HR}=1.02,95 \% \mathrm{CI}=0.88-1.18$, $p=0.78)$.

Concerning subgroup analysis for frailty patients with poor baseline pulmonary function, significant negative correlations were observed between $\mathrm{OS}$ and mean lung $\mathrm{BED}_{3}$ in cases of FEV $1 \leq 40 \%(r=-0.6, p=0.005)$ and DLCO $\leq 40 \%(r=-0.36$, $p=0.033$ ) (Figure 3). The best prognostic mean lung $\mathrm{BED}_{3}$ threshold identified on the ROC curve in terms of sensitivity and specificity for OS was $5 \mathrm{~Gy}$ for the entire population (i.e., 3.6 Gy in 3 fractions or $4.3 \mathrm{~Gy}$ in 5 fractions) and reduced to $4 \mathrm{~Gy}$ for patients with FEV $1 \leq 40 \%$ (i.e., 3 Gy in 3 fractions or 3.5 Gy in 5 fractions). Concerning all the 100 treated patients, a mean lung $\mathrm{BED}_{3} \leq 5$ Gy was significantly associated with a higher OS ( $p=0.0068)$ with a doubling of median OS from 29 months to more than 60 months (not achieved). OS at 1, 2, 3, 4, and 5 years was respectively $89.1,78.8,71.8,65.2$, and $58 \%$ for a mean lung $\mathrm{BED}_{3} \leq 5$ Gy rather than $75.6,61.8,42,36$, and $19.2 \%$ for a mean lung $\mathrm{BED}_{3}>5 \mathrm{~Gy}$ (Figure 4). Similarly, in patients with poor baseline pulmonary function (i.e., FEV $1 \leq 40 \%$ ), a mean lung $\mathrm{BED}_{3} \leq 4$ Gy was significantly associated with a higher OS ( $p=0.019)$ with a doubling of median OS from 23 months to 46 months. OS at 1, 2 and 3 years was respectively 90, 90, and $67.5 \%$ for a mean lung $\mathrm{BED}_{3} \leq 4$ Gy rather than $70,46.7$, and $23.3 \%$ for a mean lung $\mathrm{BED}_{3}>4$ Gy (Figure 3).

\section{Clinical Follow-Up and Toxicities}

At the end of follow up, lung SBRT led to $31 \%$ Grade $\leq 2$ clinically symptomatic radiation pneumonitis (RP), 14\% G1 chest wall pain, $7 \%$ transient $G \leq 2$ radiation dermatitis (4 G1 and 3 G2), $4 \%$ rib fractures after a mean period of 28 months (range: $12-45)$, and $14 \%$ G1 chest wall pain. At least 22 patients (22\%) 


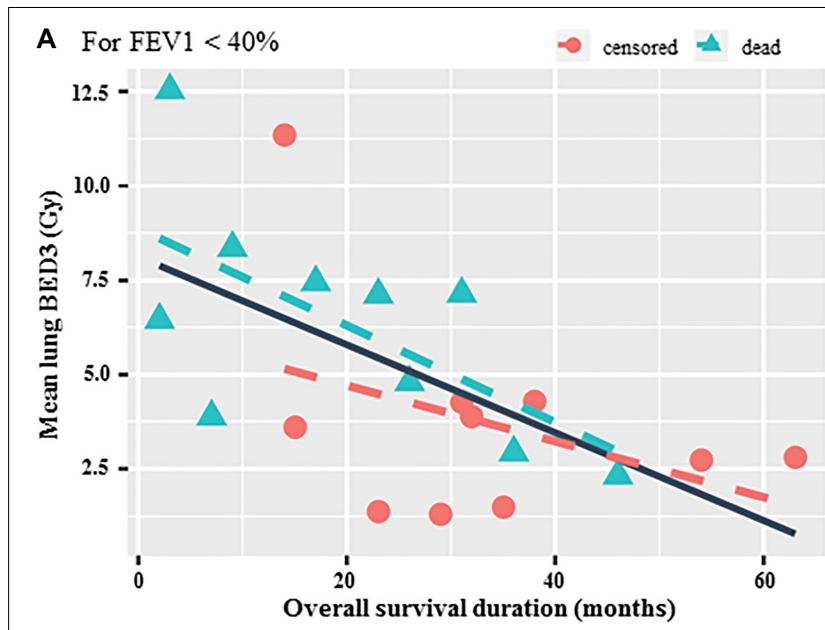

B For DLCO $<40 \% \quad \neg$ censored $\Rightarrow$ dead
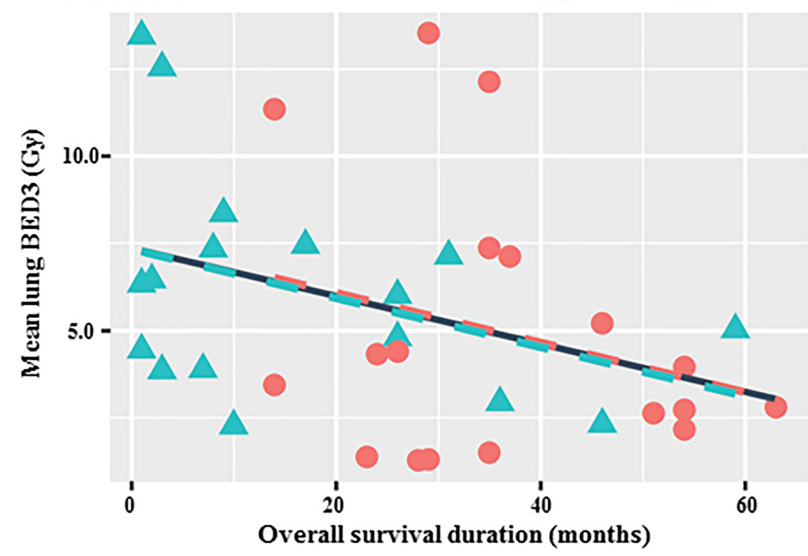

FIGURE 3 | Correlation between OS and mean lung BED3 for patients with FEV1 $<40 \%(r=-0.6, p=0.005)$ (A) and with DLCO $<40 \%(r=-0.36$, $p=0.033$ ) (B). The solid line shows correlation independently of the censored or dead patients.

died from severe pulmonary insufficiency. Significant predictive factors of clinically symptomatic $\mathrm{G} \geq 1 \mathrm{RP}$ were in univariate analysis FEV1 $(\mathrm{OR}=0.630,95 \% \mathrm{CI}=0.550-0.780, p<0.001)$, DLCO $(\mathrm{OR}=0.750,95 \% \mathrm{CI}=0.660-0.859, p<0.001)$ and mean ipsilateral lung $\mathrm{BED}_{3}(\mathrm{OR}=0.956$, 95\%CI $=0.923-$ 0.999, $p=0.043$ ). There was a trend towards mean lung $\mathrm{BED}_{3}$ ( $\mathrm{OR}=0.986,95 \% \mathrm{CI}=0.998-0.967, p=0.086)$. In multivariate analysis, FEV1 $(\mathrm{OR}=0.929,95 \% \mathrm{CI}=0.878-0.971, p=0.003)$ and DLCO $(\mathrm{OR}=0.939,95 \% \mathrm{CI}=0.886-0.984, p=0.015)$ remained significant (Table 2). No significant predictive factor of radiation dermatitis, rib fractures or chest wall pain was found. No other toxicity was observed.

\section{DISCUSSION}

To date, the present study is the first to demonstrate a significant correlation between OS and MLD after Stage I NSCLC SBRT. Moreover, this finding leads us to propose reducing published lung constraints with thresholds of 5 and $4 \mathrm{~Gy}$ in mean lung $\mathrm{BED}_{3}$ respectively for patients with FEV $1>40 \%$ and FEV $1 \leq 40 \%$.

Our lung SBRT characteristics are in agreement with international guidelines about Stage I NSCLC, especially with Timmerman et al. in the analysis of RTOG 0236 (25). Marginal prescribed dose to the edge of PTV was 54 Gy in three fractions if it met dose constraints. Concerning target volume delineation, we no longer create a CTV since it is not recommended (31). When we started to treat patients in 2012, guidelines were less clear and CTV creation was debated (26). In our study, LC and OS were respectively over 95\% and about $60 \%$ at the three-year point, which is consistent with previously published studies $(1-3,25)$. No significant predictive factor of LC was found, probably because only three local failures were observed and adequate $\mathrm{BED}_{10}$ was prescribed to the tumor.

Likewise, this study found toxicity in the same proportions as previous reports: $31 \%$ clinically symptomatic RP [about 10-20\% of patients in literature (range: 0-49\% among published studies)] with most patients having asymptomatic Grade 1 pneumonitis $(2,15-17), 14 \%$ G1 chest wall pain $[10-40 \%$ in literature (32)], $7 \%$ transient $\mathrm{G} \leq 2$ radiation dermatitis $[12-38 \%$ in literature (33)], and $4 \%$ rib fractures [0-23\% in literature (34)] without other toxicity. No significant predictive factor of chest wall pain, radiation dermatitis or rib fractures was found, probably due to meeting dose constraints (35). Significant predictive factors of RP reported in our study are in agreement with published studies concerning MLD, which is frequently mentioned (15, 17, 1921). In contrast, baseline pulmonary function (FEV1 and DLCO) was strongly and significantly correlated to RP in univariate and multivariate analyses (18). Thus, the results reported in the present study are demonstrated to be reproducible and may be applied to other studies. As compared to normo-fractionated radiotherapy, MLD corresponds to the most used parameter in predictive risk models pulmonary toxicity due to its simplicity and effectiveness $(36,37)$. Dose constraint for MLD is often $\leq 15-$ 20 , i.e., mean lung $\mathrm{BED}_{3} \leq 16-21$ Gy $(38,39)$. Estimated risk of symptomatic RP is $5,10,20,30$, and $40 \%$ for thresholds of 7,13 , 20, 24, and 27 Gy in MLD, i.e., thresholds of 7, 13, 21, 27, and 30 Gy in mean lung $\mathrm{BED}_{3}$ (39).

Radiation pneumonitis is a known important dose-limiting factor in lung cancer radiation therapy. RP is categorized into two interdependent stages: acute RP and late RP (a chronic injury stage known as pulmonary fibrosis) which can theoretically be fatal, especially if pulmonary function is already impaired. The summarized sequence of classic RP is as follows: cellular injury leads to cytokine release, cytokine recruitment of the inflammatory infiltrate causes acute pneumonitis, and the body's attempt to repair the injury results in pulmonary fibrosis (13). It is accepted that recognition of sporadic RP can be particularly difficult for clinicians because it is rare $(\approx 10 \%)$ and patients often present with severe dyspnea and/or "out-of-field" radiographic findings that may raise the possibility of other disease process (13). So we can think that RP are probably underestimated in published studies, and especially their exact relationship with the death of patients. This might be one of the explanations of why MLD was a significant prognostic factor of OS in our study. 


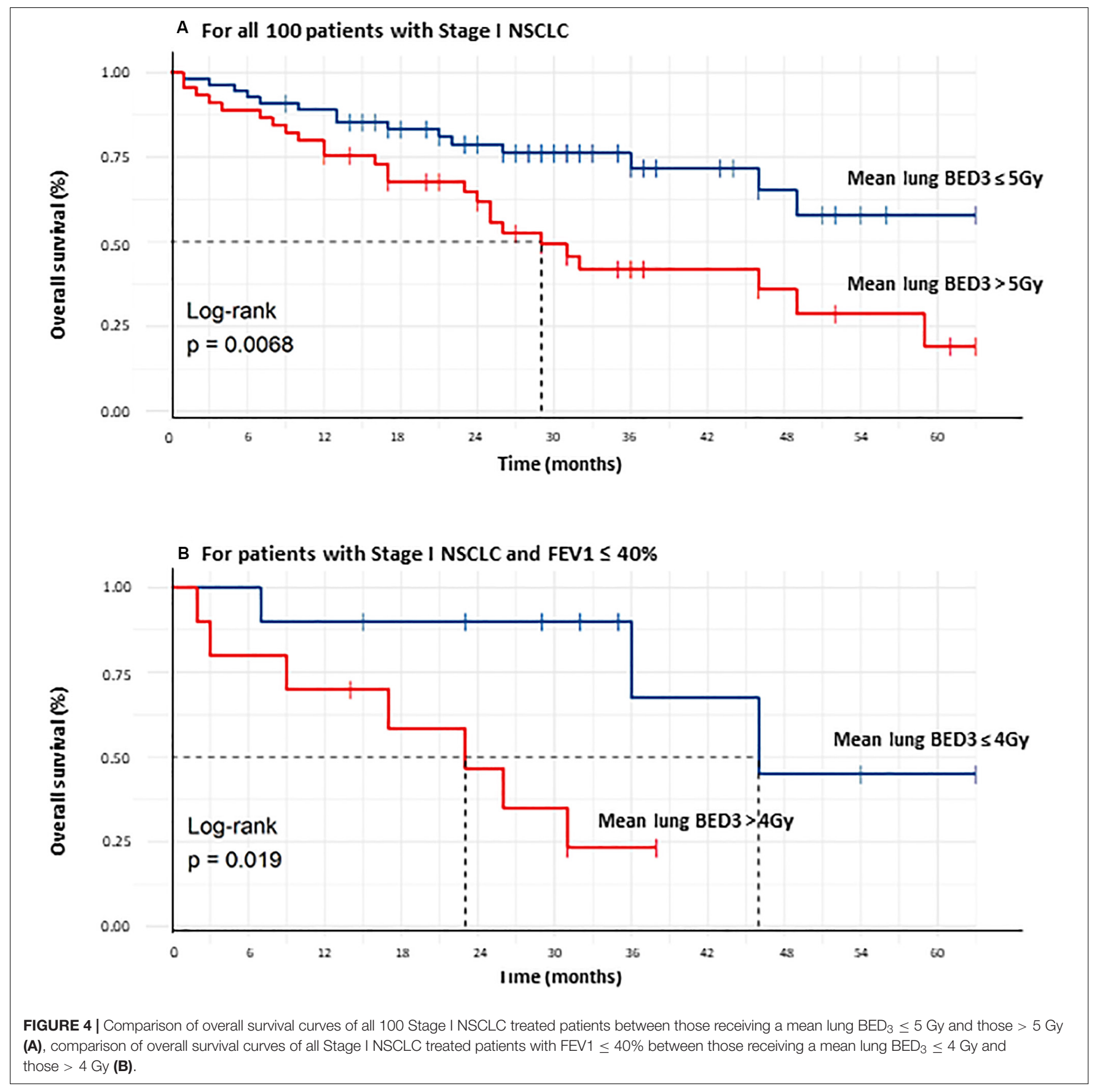

Limitations of the study were in link with the difficulty to recognize RP particularly in patients with a poor baseline pulmonary function and frequent flares of acute pulmonary insufficiency. It was very difficult to know from what patients were dying and the cause of their pulmonary insufficiency: natural and classic outcome of their comorbidities or especially related to RP? Other limitations were that study was mono institutional and not multicentric, only 100 patients were included which could have led to a lack of power for statistical analyses and data were retrospectively analyzed even if they were prospectively updated. Statistical analysis was robust and there was only one patient lost to follow-up after a period of 10 months after SBRT. Pulmonary heterogeneity, which may be a reason for false interpretation, has been taken into account by using the Monte Carlo algorithm for DCA plans and the AAA algorithm for VMAT plans. Various dose prescriptions and fractionations have been studied with the linear-quadratic model with an $\alpha / \beta$ ratio of 3 Gy which was the best method for converting the physical lung dose to predict RP (24).

Concerning PFS, PFS after lung SBRT was significantly correlated to tumor volume (GTV) in univariate and in multivariate analysis. We did not find mean lung $\mathrm{BED}_{3}$ as a 
significant prognostic factor of PFS in univariate analysis. One of the explanations might be a lack of power of our study because the lower threshold value of the $95 \%$ CI was very close to 1 (0.988). Interestingly, there was therefore a strong trend for significance when we studied mean ipsilateral lung $\mathrm{BED}_{3}$ ( $p$-value of 0.063 ; $\mathrm{HR}=2.035,95 \% \mathrm{CI}=1.000-1.072$ ).

Concerning OS, it is widely agreed that more patients die of comorbidities than of tumor progression since LC is excellent, over $95 \%$ at three years. Therefore, significant published prognostic factors to date mostly relate to comorbidities [age (4), gender (5), performance status $(4,6)$, platelet-to-lymphocyte ratio $(8,10)$, and pretreatment immune parameters $(10)]$ if the prescribed dose is sufficiently high (11). However, no relationship between toxicity and OS is demonstrated to date. Many patients treated with lung SBRT die from severe pulmonary insufficiency, but it is not easy to distinguish whether the main cause is the natural course of pulmonary or cardiovascular disease or if SBRT lung toxicity might have worsened the situation. Severe RP is probably under-evaluated in literature. It is the main toxicity factor after lung SBRT; furthermore, MLD seems to be the strongest and most reproducible dosimetric parameter of RP $(15,17,19-21)$. In addition, tumor volume is a reproducible and frequently reported significant prognostic factor of OS (57). We can also surmise that tumor volume is linked to MLD and that patients could die from a higher received MLD than GTV because LC is high. For this reason, we have made the choice to study the correlation between OS and MLD, which we have demonstrated to be significant in multivariate analysis for all patients $(\mathrm{HR}=1.14, \mathrm{CI} 95 \%=1.03-1.25, p=0.01)$ and in subgroup multivariate analysis, whether for patients with $\mathrm{FEV}_{1} \leq 40 \%(\mathrm{HR}=1.55,95 \% \mathrm{CI}=1.12-2.14, p=0.008)$ or with $\mathrm{FEV}_{1}>40 \%(\mathrm{HR}=1.14,95 \% \mathrm{CI}=1.02-1.28, p=0.021)$ or with GTV < mean GTV, i.e., $8.6 \mathrm{cc}(\mathrm{HR}=1.34$, 95\%CI $=1.06-$ $1.69, p=0.015)$. GTV and $\mathrm{FEV}_{1}$ cannot be modified while the prescribed dose can be adjusted.

Moreover, we showed in our study a significant correlation between OS and MLD with a significant threshold value of 5 Gy for $\mathrm{BED}_{3}$, i.e., $3.6 \mathrm{~Gy}$ in three fractions. A significant cut-off at 4-4.7 Gy in three fractions is reported in literature concerning the probability of RP after lung SBRT $(17,19)$. So our threshold value of $3.6 \mathrm{~Gy}$ in three fractions is not very different from that published for symptomatic RP, which enables us to assume that the threshold value of 5 Gy for OS may be related to RP. Thresholds values may have to be reduced to 5 Gy (i.e., 3.6 Gy in 3 fractions or 4.3 Gy in 5 fractions) and 4 Gy (i.e., 3 Gy in 3 fractions or 3.5 Gy in 5 fractions) in

\section{REFERENCES}

1. Baumann P, Nyman J, Hoyer M, Wennberg B, Gagliardi G, Lax I, et al. Outcome in a prospective phase II trial of medically inoperable stage I nonsmall-cell lung cancer patients treated with stereotactic body radiotherapy. $J$ Clin Oncol Off J Am Soc Clin Oncol. (2009) 27:3290-6. doi: 10.1200/JCO.2008. 21.5681

2. Abel S, Hasan S, Horne ZD, Colonias A, Wegner RE. Stereotactic body radiation therapy in early-stage NSCLC: historical review, contemporary evidence and future implications. Lung Cancer Manag. (2019) 8:LMT09. doi: 10.2217/lmt-2018-0013 mean lung $\mathrm{BED}_{3}$ respectively for patients with $\mathrm{FEV} 1>40 \%$ and FEV1 $\leq 40 \%$, as our study suggests, to have an impact on OS. These two thresholds values are totally in agreement because we may have to be more careful to treat frailty patients and probably we may have to reduce prescribed dose for these patients. We therefore recommend using effective algorithms that take into account pulmonary heterogeneity and limiting PTV irradiated volume to a minimum by reducing margins (not creating a CTV or using gating or tracking techniques). This is particularly crucial for frailty patients with poor baseline pulmonary function $(\mathrm{FEV} 1 \leq 40 \%)$.

\section{CONCLUSION}

In summary, our study demonstrates a significant and strong correlation between $\mathrm{OS}$ and mean lung $\mathrm{BED}_{3}$, confirmed in univariate and multivariate analysis in all patients, in subgroup analysis and in survival curves analysis. Higher mean lung $\mathrm{BED}_{3}$ is always strongly and significantly associated with a poorer OS. Moreover, significant mean lung $\mathrm{BED}_{3}$ threshold values have here been shown to correlate with OS: 5 Gy for the entire population (i.e., 3.6 Gy in 3 fractions or $4.3 \mathrm{~Gy}$ in 5 fractions) and $4 \mathrm{~Gy}$ for patients with FEV $1 \leq 40 \%$ (i.e., 3 Gy in 3 fractions or 3.5. Gy in 5 fractions). Stay below these threshold values significantly enabled a doubling of median OS.

\section{DATA AVAILABILITY STATEMENT}

The datasets generated for this study are available on request to the corresponding author.

\section{ETHICS STATEMENT}

Study ethics approval was obtained on 06 December 2019 (CECIC Rhône-Alpes-Auvergne, Grenoble, IRB 5921).

\section{AUTHOR CONTRIBUTIONS}

GD and IM analyzed the data. GD wrote and revised the manuscript. JB, VC, $\mathrm{VD}, \mathrm{ML}$, and $\mathrm{AB}-\mathrm{C}$ also revised the manuscript. All authors have actively participated in the data acquisition, commented, and approved the final version of the manuscript.

3. Prezzano KM, Ma SJ, Hermann GM, Rivers CI, Gomez-Suescun JA, Singh AK. Stereotactic body radiation therapy for non-small cell lung cancer: A review. World J Clin Oncol. (2019) 10:14-27. doi: 10.5306/wjco.v10. i1.14

4. Spratt DE, Wu AJ, Adeseye V, Din SU, Shaikh F, Woo KM, et al. Recurrence patterns and second primary lung cancers after stereotactic body radiation therapy for early-stage non-small-cell lung cancer: implications for surveillance. Clin Lung Cancer. (2015) 17:177-83.e2. doi: 10.1016/j.cllc.2015. 09.006

5. Matsuo Y, Shibuya K, Nagata Y, Takayama K, Norihisa Y, Mizowaki T, et al. Prognostic factors in stereotactic body radiotherapy for non-small-cell lung 
cancer. Int J Radiat Oncol. (2011) 79:1104-11. doi: 10.1016/j.ijrobp.2009.12. 022

6. Kohutek ZA, Wu AJ, Zhang Z, Foster A, Din SU, Yorke ED, et al. FDGPET maximum standardized uptake value is prognostic for recurrence and survival after stereotactic body radiotherapy for non-small cell lung cancer. Lung Cancer Amst Neth. (2015) 89:115-20. doi: 10.1016/j.lungcan.2015. 05.019

7. Chi A, Liao Z, Nguyen NP, Xu J, Stea B, Komaki R. Systemic review of the patterns of failure following stereotactic body radiation therapy in earlystage non-small-cell lung cancer: clinical implications. Radiother Oncol. (2010) 94:1-11. doi: 10.1016/j.radonc.2009.12.008

8. Shi S, Ye L, Zhao Q, Hu Y, Huang Y, Chen G, et al. Prognostic index score predicts outcome of patients with Stage I non-small cell lung cancer after stereotactic body radiation therapy. Jpn J Clin Oncol. (2019) 49:367-72. doi: $10.1093 /$ jjco/hyy205

9. Chang JY, Liu H, Balter P, Komaki R, Liao Z, Welsh J, et al. Clinical outcome and predictors of survival and pneumonitis after stereotactic ablative radiotherapy for stage I non-small cell lung cancer. Radiat Oncol. (2012) 7:152. doi: 10.1186/1748-717X-7-152

10. Shaverdian N, Veruttipong D, Wang J, Schaue D, Kupelian P, Lee P. Pretreatment immune parameters predict for overall survival and toxicity in early-stage non-small-cell lung cancer patients treated with stereotactic body radiation therapy. Clin Lung Cancer. (2016) 17:39-46. doi: 10.1016/j.cllc.2015. 07.007

11. Stahl JM, Ross R, Harder EM, Mancini BR, Soulos PR, Finkelstein SE, et al. The effect of biologically effective dose and radiation treatment schedule on overall survival in stage I non-small cell lung cancer patients treated with stereotactic body radiation therapy. Int J Radiat Oncol Biol Phys. (2016) 96:1011-20. doi: 10.1016/j.ijrobp.2016.08.033

12. Martin A, Gaya A. Stereotactic body radiotherapy: a review. Clin Oncol. (2010) 22:157-72. doi: 10.1016/j.clon.2009.12.003

13. Hanania AN, Mainwaring W, Ghebre YT, Hanania NA, Ludwig M. Radiationinduced lung injury: assessment and management. Chest. (2019) 156:150-62. doi: $10.1016 /$ j.chest.2019.03.033

14. Haasbeek CJA, Lagerwaard FJ, Slotman BJ, Senan S. Outcomes of stereotactic ablative radiotherapy for centrally located early-stage lung cancer. $J$ Thorac Oncol Off Publ Int Assoc Study Lung Cancer. (2011) 6:2036-43. doi: 10.1097/ JTO.0b013e31822e71d8

15. Matsuo Y, Shibuya K, Nakamura M, Narabayashi M, Sakanaka K, Ueki $\mathrm{N}$, et al. Dose-volume metrics associated with radiation pneumonitis after stereotactic body radiation therapy for lung cancer. Int $J$ Radiat Oncol Biol Phys. (2012) 83:e545-9. doi: 10.1016/j.ijrobp.2012. 01.018

16. Baker R, Han G, Sarangkasiri S, DeMarco M, Turke C, Stevens CW, et al. Clinical and dosimetric predictors of radiation pneumonitis in a large series of patients treated with stereotactic body radiation therapy to the lung. Int J Radiat Oncol Biol Phys. (2013) 85:190-5. doi: 10.1016/j.ijrobp.2012. 03.041

17. Zhao J, Yorke ED, Li L, Kavanagh BD, Li XA, Das S, et al. Simple factors associated with radiation-induced lung toxicity after stereotactic body radiation therapy of the thorax: a pooled analysis of 88 studies. Int J Radiat Oncol Biol Phys. (2016) 95:1357-66. doi: 10.1016/j.ijrobp.2016. 03.024

18. Henderson M, McGarry R, Yiannoutsos C, Fakiris A, Hoopes D, Williams $\mathrm{M}$, et al. Baseline pulmonary function as a predictor for survival and decline in pulmonary function over time in patients undergoing stereotactic body radiotherapy for the treatment of stage I non-small-cell lung cancer. Int J Radiat Oncol Biol Phys. (2008) 72:404-9. doi: 10.1016/j.ijrobp.2007. 12.051

19. Barriger RB, Forquer JA, Brabham JG, Andolino DL, Shapiro RH, Henderson $\mathrm{MA}$, et al. A dose-volume analysis of radiation pneumonitis in non-small cell lung cancer patients treated with stereotactic body radiation therapy. Int J Radiat Oncol Biol Phys. (2012) 82:457-62. doi: 10.1016/j.ijrobp.2010. 08.056

20. Lu C, Lei Z, Wu H, Lu H. Evaluating risk factors of radiation pneumonitis after stereotactic body radiation therapy in lung tumor: meta-analysis of 9 observational studies. PLoS One. (2018) 13:e0208637. doi: 10.1371/journal. pone. 0208637
21. Parker SM, Siochi RA, Wen S, Mattes MD. Impact of tumor size on local control and pneumonitis after stereotactic body radiation therapy for lung tumors. Pract Radiat Oncol. (2019) 9:e90-7. doi: 10.1016/j.prro.2018. 09.003

22. Yamashita $H$, Takahashi W, Haga A, Nakagawa K. Radiation pneumonitis after stereotactic radiation therapy for lung cancer. World J Radiol. (2014) 6:708-15. doi: 10.4329/wjr.v6.i9.708

23. Biau J, Bellière A, Verrelle P, Lapeyre M. Excluding either gross tumor volume or planning target volume from the normal lung volume in lung cancer irradiation: evaluation of the dosimetric impact. Pract Radiat Oncol. (2013) 3:e79-85. doi: 10.1016/j.prro.2012.06.001

24. Borst GR, Ishikawa M, Nijkamp J, Hauptmann M, Shirato H, Bengua G, et al. Radiation pneumonitis after hypofractionated radiotherapy: evaluation of the LQ(L) model and different dose parameters. Int J Radiat Oncol Biol Phys. (2010) 77:1596-603. doi: 10.1016/j.jijrobp.2009.10.015

25. Timmerman R, Paulus R, Galvin J, Michalski J, Straube W, Bradley J, et al. STereotactic body radiation therapy for inoperable early stage lung cancer. JAMA. (2010) 303:1070-6. doi: 10.1001/jama.2010.261

26. De Ruysscher D, Faivre-Finn C, Nestle U, Hurkmans CW, Le Péchoux C, Price A, et al. European organisation for research and treatment of cancer recommendations for planning and delivery of high-dose, high-precision radiotherapy for lung cancer. J Clin Oncol Off J Am Soc Clin Oncol. (2010) 28:5301-10. doi: 10.1200/JCO.2010.30.3271

27. Giraud P, Antoine M, Larrouy A, Milleron B, Callard P, De Rycke $\mathrm{Y}$, et al. Evaluation of microscopic tumor extension in non-smallcell lung cancer for three-dimensional conformal radiotherapy planning. Int J Radiat Oncol. (2000) 48:1015-24. doi: 10.1016/S0360-3016(00) 00750-1

28. Xiao Y, Papiez L, Paulus R, Timmerman R, Straube WL, Bosch WR, et al. Dosimetric evaluation of heterogeneity corrections for RTOG 0236: stereotactic body radiotherapy of inoperable stage I-II non-small-cell lung cancer. Int J Radiat Oncol Biol Phys. (2009) 73:1235-42. doi: 10.1016/j.ijrobp. 2008.11.019

29. Therasse P, Arbuck SG, Eisenhauer EA, Wanders J, Kaplan RS, Rubinstein L, et al. New guidelines to evaluate the response to treatment in solid tumors. European Organization for Research and Treatment of Cancer, National Cancer Institute of the United States, National Cancer Institute of Canada. J Natl Cancer Inst. (2000) 92:205-16. doi: 10.1093/jnci/92. 3.205

30. Bollineni VR, Widder J, Pruim J, Langendijk JA, Wiegman EM. Residual ${ }^{18} \mathrm{~F}-$ FDG-PET uptake 12 weeks after stereotactic ablative radiotherapy for stage I non-small-cell lung cancer predicts local control. Int J Radiat Oncol Biol Phys. (2012) 83:e551-5. doi: 10.1016/j.ijrobp.2012.01.012

31. Timmerman RD, Paulus R, Pass HI, Gore EM, Edelman MJ, Galvin J, et al. Stereotactic body radiation therapy for operable early-stage lung cancer. JAMA Oncol. (2018) 4:1263-6. doi: 10.1001/jamaoncol.2018.1251

32. Din SU, Williams EL, Jackson A, Rosenzweig KE, Wu AJ, Foster A, et al. Impact of fractionation and dose in a multivariate model for radiation-induced chest wall pain. Int J Radiat Oncol Biol Phys. (2015) 93:418-24. doi: 10.1016/j.ijrobp. 2015.06.014

33. Hoppe BS, Laser B, Kowalski AV, Fontenla SC, Pena-Greenberg E, Yorke ED, et al. Acute skin toxicity following stereotactic body radiation therapy for stage I non-small-cell lung cancer: who's at risk? Int J Radiat Oncol Biol Phys. (2008) 72:1283-6. doi: 10.1016/j.ijrobp.2008.08.036

34. Nambu A, Onishi H, Aoki S, Tominaga L, Kuriyama K, Araya M, et al. Rib fracture after stereotactic radiotherapy for primary lung cancer: prevalence, degree of clinical symptoms, and risk factors. BMC Cancer. (2013) 13:68. doi: 10.1186/1471-2407-13-68

35. Timmerman RD. An overview of hypofractionation and introduction to this issue of seminars in radiation oncology. Semin Radiat Oncol. (2008) 18:215-22. doi: 10.1016/j.semradonc.2008.04.001

36. Seppenwoolde Y, Lebesque JV, de Jaeger K, Belderbos JSA, Boersma LJ, Schilstra C, et al. Comparing different NTCP models that predict the incidence of radiation pneumonitis. Normal tissue complication probability. Int J Radiat Oncol Biol Phys. (2003) 55:724-35. doi: 10.1016/s0360-3016(02) 03986-x

37. Jain V, Niezink AGH, Frick M, Doucette A, Mendes A, Simone CB, et al. Updating photon-based normal tissue complication probability 
models for pneumonitis in lung cancer patients treated with proton beam therapy. Pract Radiat Oncol. (2020) 102:S223-4. doi: 10.1016/j.prro.2020. 04.005

38. Kong F-M, Hayman JA, Griffith KA, Kalemkerian GP, Arenberg D, Lyons S, et al. Final toxicity results of a radiation-dose escalation study in patients with non-small-cell lung cancer (NSCLC): predictors for radiation pneumonitis and fibrosis. Int J Radiat Oncol Biol Phys. (2006) 65:1075-86. doi: 10.1016/j. ijrobp.2006.01.051

39. Marks LB, Bentzen SM, Deasy JO, Kong F-MS, Bradley JD, Vogelius IS, et al. Radiation dose-volume effects in the lung. Int J Radiat Oncol Biol Phys. (2010) 76:S70-6. doi: 10.1016/j.ijrobp.2009.06.091
Conflict of Interest: The authors declare that the research was conducted in the absence of any commercial or financial relationships that could be construed as a potential conflict of interest.

Copyright () 2020 Dupic, Biau, Molnar, Chassin, Dedieu, Lapeyre and BellièreCalandry. This is an open-access article distributed under the terms of the Creative Commons Attribution License (CC BY). The use, distribution or reproduction in other forums is permitted, provided the original author(s) and the copyright owner(s) are credited and that the original publication in this journal is cited, in accordance with accepted academic practice. No use, distribution or reproduction is permitted which does not comply with these terms. 